\title{
Pyrene removal from contaminated soils by modified Fenton oxidation using iron nano particles
}

\author{
Sahand Jorfi ${ }^{1}$, Abbas Rezaee ${ }^{1 *}$, Ghasem-ali Moheb-ali ${ }^{2}$ and Nemat alah Jaafarzadeh ${ }^{3}$
}

\begin{abstract}
Background: The problems related to conventional Fenton oxidation, including low pH required and production of considerable amounts of sludge have led researchers to investigate chelating agents which might improve the operating range of $\mathrm{pH}$ and the use of nano iron particle to reduce the excess sludge. The pyrene removal from contaminated soils by modified Fenton oxidation at neutral $\mathrm{pH}$ was defined as the main objective of the current study.
\end{abstract}

Methods: Varying concentrations of $\mathrm{H}_{2} \mathrm{O}_{2}(0-500 \mathrm{mM})$ and iron nano oxide $(0-60 \mathrm{mM})$, reaction times of $0.5-24$ hours and variety of chelating agents including sodium pyrophosphate, sodium citrate, ethylene diamine tetraacetic, fulvic and humic acid were all investigated at pyrene concentration levels of $100-500 \mathrm{mg} / \mathrm{kg}$.

Results: By applying the following conditions $\left(\mathrm{H}_{2} \mathrm{O}_{2}\right.$ concentration of $300 \mathrm{mM}$, iron nano oxide of $30 \mathrm{mM}$, sodium pyrophosphate as chelating agent, $\mathrm{pH} 3$ and reaction time of 6 hours) the pyrene removal efficiency at an initial concentration of $100 \mathrm{mg} / \mathrm{kg}$ was found to be $99 \%$. As a result, the pyrene concentration was reduced from 100 to $93 \mathrm{mg} / \mathrm{kg}$ once the above optimum conditions are met.

Conclusions: In this research, the modified Fenton oxidation using iron nano oxide at optimum conditions is introduced as an efficient alternative method in lab scale for chemical remediation or pre-treatment of soils contaminated by pyrene at neutral pH.

Keywords: Soil pollution, Pyrene, Modified fenton oxidation, Iron nano oxide, Chelating agent

\section{Introduction}

Polycyclic Aomatic Hydrocarbons (PAHs) are persistent contaminants resulting from natural or anthropogenic processes. Industrial processes, petroleum product spillages and incomplete combustion of fossil fuels have led to PAHs accumulation during past decades [1]. Environmental contamination to PAHs and specially soil pollution near the gas stations or petrochemical industries is verified in several reports. The concerning characteristics of PAHs is their hydrophobic nature which increases the toxicity to the human and environment [2]. Therefore, they are easily adsorbed to soil matrix and make tight bindings with Soil Organic Matter (SOMs) [3].

\footnotetext{
* Correspondence: rezaee@modares.ac.ir

${ }^{1}$ Department of Environmental Health Engineering, School of Medical

Sciences, Tarbiat Modares University, Tehran, Iran

Full list of author information is available at the end of the article
}

Pyrene is a four-ring PAH with low biodegradability and high persistency in environment, which is considered as a priority pollutant by US EPA because of its carcinogenic and mutagenic effects [4-6]. Various methods including solvent extraction, phytoremediation, elecrokinetic and photocatalytic remediation, thermal destruction, chemical remediation and bioremediation are evaluated and studied for PAHs removal and transformations. Chemical remediation and bioremediation are preferred because of their superior advantages. However, bioremediation is restricted due to being time consuming, degradation of only one or few contaminants with a specified strain, the possible toxicity of pollutant to the bacterial strains and high toxicity and persistency of majority of hydrocarbons $[7,8]$.

Since the chemical oxidation approaches act vigorously and rapidly and are not sensitive to the type of pollutants, they can be considered as a suitable alternative for

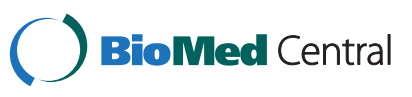

(c) 2013 Jorfi et al.; licensee BioMed Central Ltd. This is an Open Access article distributed under the terms of the Creative Commons Attribution License (http://creativecommons.org/licenses/by/2.0), which permits unrestricted use, distribution, and reproduction in any medium, provided the original work is properly cited. 
bioremediation or can be used as pre or post-treatment in a sequencing system with bioremediation [9]. The required time for remediation can be significantly reduced using Advanced Oxidation Processes (AOPs) like Fenton oxidation. In conventional Fenton oxidation, $\mathrm{H}_{2} \mathrm{O}_{2}$ reacts with soluble $\mathrm{Fe}^{2+}$ and yields hydroxyl radical $\left(\mathrm{OH}^{*}\right)$ and $\mathrm{Fe}^{3+}$ (equation 1). Yap et al. [10] demonstrated the efficiency of Fenton oxidation for pyrene, anthracene and phenanthrene removal in soil with kinetic constants ranging from $2.5 \times 10^{-1} \mathrm{~h}^{-1}$ to $3.9 \times 10^{-1} \mathrm{~h}^{-1}$ [10]. Also, Kulic et al (2006) reported that Fenton oxidation of PAHs obey pseudo first order reactions that an increase in Fenton reagents led to improvement of removal efficiency [11]. Hydroxyl radical is a non selective oxidant with redox potential of 2.8 , which is able to break down PAHs and many other organic persistent pollutants. In conventional Fenton reaction, the regeneration of $\mathrm{Fe}^{2+}$ from produced $\mathrm{Fe}^{3+}$ is necessary (equation 2), which needs acidic $\mathrm{pH}$ to prevent $\mathrm{Fe}^{3+}$ precipitation as iron hydroxide [12].

$$
\begin{aligned}
& \mathrm{Fe}^{2+}+\mathrm{H}_{2} \mathrm{O}_{2} \rightarrow \mathrm{Fe}^{3+} \mathrm{OH}^{*}+\mathrm{OH}^{-} \\
& \mathrm{Fe}^{3+}+\mathrm{H}_{2} \mathrm{O}_{2} \rightarrow \mathrm{Fe}^{2+}+\mathrm{H}^{+}+\mathrm{HO}_{2}{ }^{*}
\end{aligned}
$$

This low pH can adversely affect the natural soil systems and change its characteristics, and on the other hand is not adaptable with the possible following bioprocess $[13,14]$. Chelating agents (CAs) are added to conventional Fenton reaction to enhance the catalytic activity of soluble iron and prevent iron loss due to its precipitation or binding to hydrophobic portions of soil organic matters at neutral $\mathrm{pH}$. This modification is called modified Fenton oxidation [15]. The chelating agents with their multidentate features and cyclic structure can bind metal ions to form heterocyclic rings. In addition to organic chelating agents like ethylene diamine tetra acetic acid (EDTA), oxalic acid (OA), sodium citrate (SC), fulvic acid (FA), humic acid (HA), cathecol and acetic acid, modified Fenton oxidation with inorganic CAs is also studied. Venny et al. [16] considered sodium pyrophosphate as a chelating agent for PAHs removal in contaminated soils in neutral $\mathrm{pH}$ [16]. The most important advantages of inorganic CAs include the less scavenging effects to hydroxyl radicals and not increasing the total carbon content of the soil during treatment. Pyrophosphate is successfully used for Fenton reactions at neutral $\mathrm{pH}$ and the phosphate ions are a supplementary nutrient source for soil matrix and microbial metabolism [16]. Another difficulty in Fenton reaction is rapid dissociation of $\mathrm{H}_{2} \mathrm{O}_{2}$ with $\mathrm{Fe}{ }^{2+}$, which usually hinders effective application of Fenton oxidation. Therefore, $\mathrm{Fe}^{3+}$ is used instead of $\mathrm{Fe}^{2+}$ to prevent the short half life of $\mathrm{H}_{2} \mathrm{O}_{2}$ in slurry soil [17]. Iron nano oxides have been frequently studied for remediation of contaminated sites in recent years, because of their advantages including high reactivity, less amounts of excess sludge and secondary metabolites, effective degradation of contaminants and destruction of a wide range of pollutants. Rusevova et al. [18] studied nano-sized magnetic iron oxides as catalysts for heterogeneous Fentonlike reactions [18]. Also Grieger et al. [19] studied the environmental benefits and the risks of iron nano particle for in situ remediation [19]. In the current study, the application of iron nano oxides in a modified Fenton oxidation using organic and inorganic CAs for pyrene removal was defined as the main objective to determine the feasibility of the process at natural $\mathrm{pH}$ and also possible superiority of iron nano oxides over iron salts.

\section{Materials and Methods \\ Chemicals}

pyrene (96\%) for preparation of the stock solution of $1 \mathrm{~g} / \mathrm{L}$ and all solvents including $\mathrm{n}$-hexane, methanol and acetone were of analytical grade and purchased from [Merck Company]. Hydrogen peroxide (30\%), $\mathrm{H}_{2} \mathrm{SO}_{4}$ (98\%), $\mathrm{HCl}, \mathrm{NaOH}, \mathrm{EDTA}$, sodium citrate, sodium pyrophosphate, $\mathrm{HgCl}_{2}, \mathrm{FeSO}_{4} .7 \mathrm{H}_{2} \mathrm{O}$ were also purchased from Merck Company. Humic and fulvic acid were supplied by Fluka Company. Iron nano oxides (Both $\mathrm{Fe}_{3} \mathrm{O}_{4}$ and $\mathrm{Fe}_{2} \mathrm{O}_{3}$ were confirmed by XRD analysis (Figure 1) were prepared from Zist Shimi Azma Corporation.

\section{Soil preparation}

The soil was derived from an oil industrial zone in south of Iran. The Soil samples were collected from the upper layer $(0-40 \mathrm{~cm})$ by soil cores, air-dried, and passed through a $2-\mathrm{mm}$ sieve. Then, the sieved soils were homogenized by shaking, washed three times with acetone, autoclaved and stored in plastic containers at $4^{\circ} \mathrm{C}$. The resulting samples were spiked with a solution of $100 \mathrm{mg} / \mathrm{kg}$ pyrene dissolved in n-hexane, shacked and left in hood for $24 \mathrm{~h}$, till the $\mathrm{n}$-hexane evaporated. The stock solution of pyrene was placed on a shaker for $1 \mathrm{mi}$ nute before spiking. For simulation of an old soil contamination, a portion of spiked soil sample was aged for one year and then used in experiments [20]. The soil was analyzed for physical and chemical characteristics by Tarbiat Modares University Engineering Soils Testing Lab, Iran (Table 1). The chemical composition of the soil sample was determined byX Ray Flourescence (XRF) analysis.

The soil classification was found to be silty sand with $1.02 \%$ clay. Among all of its constituents, Natural Organic Matter (NOM) and native iron were important regarding Fenton oxidation. NOM plays an important role in scavenging $\mathrm{OH}^{*}$ radical needed for $\mathrm{PAH}$ oxidation and iron content plays a catalytic role for decomposition of $\mathrm{H}_{2} \mathrm{O}_{2}$. The primary concentration of combustible or volatile content (as an indirect indicator of $\mathrm{NOM}$ ) and 


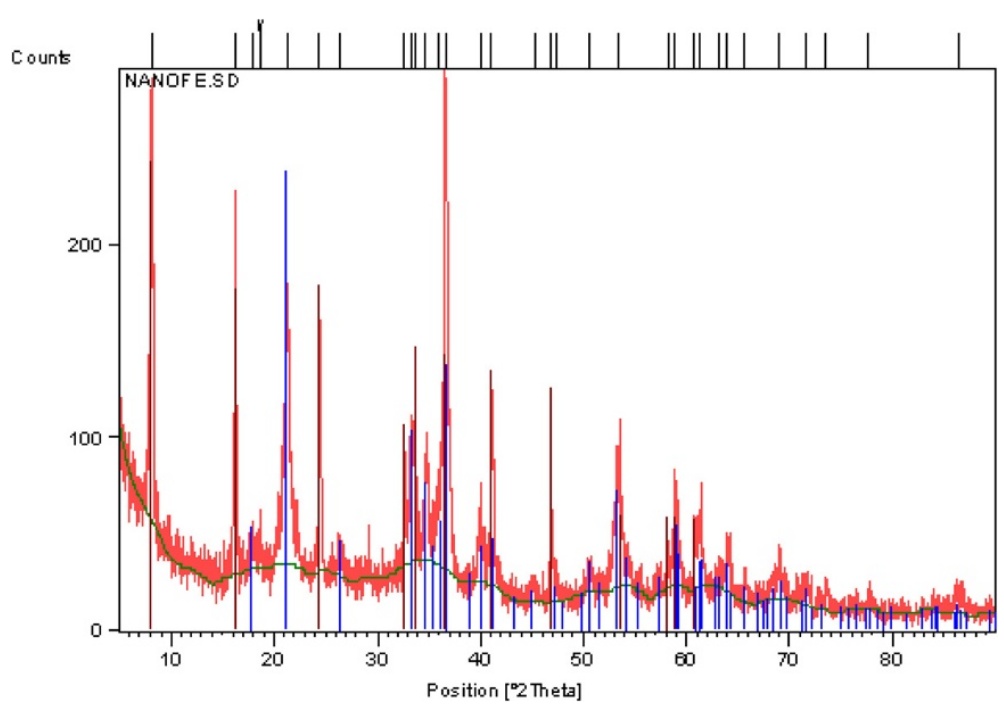

Figure 1 The XRD analysis of iron nano oxides.

Fe oxides in the soil sample were 107, and $4.155 \mathrm{~g} / \mathrm{kg}$, respectively.

\section{Modified Fenton oxidation of pyrene}

Following soil spiking and preparation, the contaminated samples were subjected to modified Fenton oxidation in the slurry phase. A $5 \mathrm{~g}$ soil sample containing $100 \mathrm{mg} / \mathrm{kg}$ pyrene was placed in a $100-\mathrm{mL}$ glass flask with screw cap and then $15 \mathrm{~mL}$ of distilled water containing $0.2 \% \mathrm{HgCl}_{2}(\mathrm{~W} / \mathrm{V})$ ( to inhibit the potential biological activity) was added to make the slurry phase (water : soil , 3:1 w/w) [21].

The experimental procedure was designed according to one factor at the time experimental design. In the first run, the iron nano oxide at concentration of $5 \mathrm{mM}$ was added to each flask and mixed for 10 minute to insure the homogenous distribution of nano oxides in the soil

Table 1 The soil characteristics

\begin{tabular}{cccc}
\hline Characteristic & Value (\%) & Characteristic & Value (\%) \\
\hline Soil type & Silty sand & $\mathrm{L} . \mathrm{O} . \mathrm{I}$ & 10.7 \\
Sand & 74.3 & $\mathrm{Na}_{2} \mathrm{O}$ & 1.944 \\
Clay & 1.02 & $\mathrm{MgO}$ & 2.046 \\
Silt & 24.68 & $\mathrm{Al}_{2} \mathrm{O}_{3}$ & 17.095 \\
Specific surface area $\left(\mathrm{m}^{2} / \mathrm{g}\right)$ & 5.39 & $\mathrm{SiO}_{2}$ & 54.797 \\
Moisture content (\%) & 6.78 & $\mathrm{P}_{2} \mathrm{O}_{5}$ & 0.202 \\
$\mathrm{Fe}_{2} \mathrm{O}_{3}$ & 0.4155 & $\mathrm{~K}_{2} \mathrm{O}$ & 3.163 \\
$\mathrm{Cu}$ & 0.158 & $\mathrm{CaO}$ & 8.842 \\
$\mathrm{Sr}$ & 0.047 & $\mathrm{TiO}_{2}$ & 0.569 \\
$\mathrm{Zr}$ & 0.019 & - & - \\
\hline
\end{tabular}

medium. The $\mathrm{pH}$ of the mixture was adjusted to 3 using $2 \mathrm{~N} \mathrm{HCl}$.

The reaction was initiated by gradual (five steps during the whole reaction time) addition of varying concentrations of $30 \% \mathrm{H}_{2} \mathrm{O}_{2}(0-500 \mathrm{mM} ; 0.155,0.31, .0 .47,0.62$, $0.78 \mathrm{~mL} 30 \% \mathrm{H}_{2} \mathrm{O}_{2}$ containing 51, 102, 153, 204 and $255 \mathrm{mg} \mathrm{H} \mathrm{H}_{2} \mathrm{O}_{2} / 15 \mathrm{~mL}$, respectively) to each flask. The homogeneity was provided by shaking the samples at $180 \mathrm{rpm}$ (IKM $4000 \mathrm{ci}$, Germany) at $30 \pm 0.5{ }^{\circ} \mathrm{C}$. After 30 minutes, the reaction was terminated with an addition of $1 \mathrm{~mL}$ of $1.5 \mathrm{M}$ sodium thiosulphate. In the second run, the effect of varying concentrations of iron nano oxide $(5-60 \mathrm{mM} ; 14.625,29.25,58.5,87.75,117$, 146.25 and $175.5 \mathrm{mg}$ Iron nano powder $/ 15 \mathrm{~mL}$ ) were studied at $\mathrm{pH} 3$, contact time of 30 minutes and the optimum $\mathrm{H}_{2} \mathrm{O}_{2}$ concentration derived from the first run.

In the third run, varying contact times $(0.5-24 \mathrm{~h})$ were studied at optimum $\mathrm{H}_{2} \mathrm{O}_{2}$ and $\mathrm{Fe}^{3+}$ concentrations at $\mathrm{pH}$ 3. Then, according to the optimum conditions obtained from the previous runs, the pyrene removal efficiency was investigated at $\mathrm{pH} 7$ in the presence of sodium pyrophosphate (as inorganic CA) and EDTA, FA, $\mathrm{HA}$ and SC (as organic CA).

In order to assess the effect of each chelating agent on removal efficiency, non parametric Kruskal Wallis test was used for statistical analysis. Kruskal Wallis test was selected because we had to deal with a limited number of variables (including chelating agent) and repetition (three times). Finally, higher pyrene concentration and the aged soil sample were investigated according to the optimum conditions at $\mathrm{pH} 7$ to simulate the process efficiency for field applications with aged and highly contaminated soils by PAHs. It is 
worth noting that all experiments were conducted in triplicate.

\section{Pyrene extraction and quantification}

The residual pyrene in the soil sample was extracted using an ultrasound device according to EPA method 3550B. Breifly; the sample was placed into a special tube filled with a mixture of $\mathrm{n}$-hexane and acetone $(1: 1 \mathrm{v} / \mathrm{v})$. After the extraction, it was centrifuged for $10 \mathrm{~min}$ at $6000 \mathrm{rpm}$ and filtered by PTFE. A portion of the filtered solution was removed for final analysis [22]. The concentration of pyrene was determined by gas chromatography (GC) system (Chrompack CP 9001) equipped with a flame ionization detector (FID) using (HP-5) capillary column ( $30 \mathrm{~m}, 0.32 \mathrm{~mm}$ i.d. and $0.2 \mu \mathrm{m}$ film thickness). Nitrogen was used as carrier gas at a rate of $2 \mathrm{~mL} / \mathrm{min}$. The temperature program was as follows: the column temperature was held at $120^{\circ} \mathrm{C}$ for $1 \mathrm{~min}$ and then raised to $240^{\circ} \mathrm{C}$ at a rate of $20^{\circ} \mathrm{C} / \mathrm{min}$, again held for $1 \mathrm{~min}$. The injector and detector temperatures were set at 250 and $300^{\circ} \mathrm{C}$, respectively.

\section{Results}

Optimum concentration of $\mathrm{H}_{2} \mathrm{O}_{2}$ and iron nano oxide The effect of varying $\mathrm{H}_{2} \mathrm{O}_{2}$ concentrations on pyrene removal efficiency (at an initial concentration of $100 \mathrm{mg} / \mathrm{kg}$ ) was investigated and presented in Figure 2. As $\mathrm{H}_{2} \mathrm{O}_{2}$ concenteration rises, the removal of pyrene is increased and finally leveled off. The maximum removal efficiency of $43 \%$ was observed at the $\mathrm{H}_{2} \mathrm{O}_{2}$ concentration of $300 \mathrm{mM}$, as can be seen in Figure 2. Therefore, $\mathrm{H}_{2} \mathrm{O}_{2}$ concentration of $300 \mathrm{mM}$ was considered as the optimum value for further expriments.

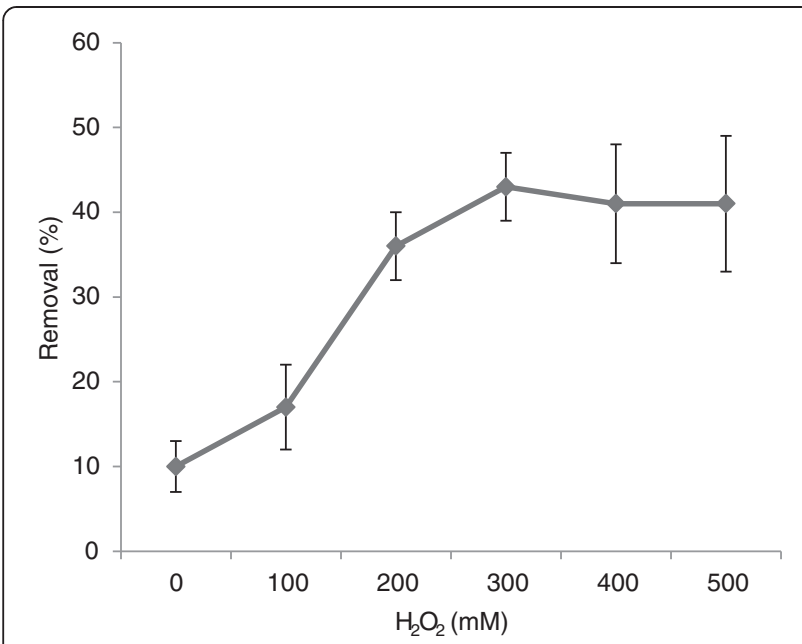

Figure 2 The pyrene removal efficiency in varying $\mathrm{H}_{2} \mathrm{O}_{2}$ concentrations of 0-500 mM, reaction time of $30 \mathrm{~min}, \mathrm{pH} 3$ and iron nano oxides concentration of $5 \mathrm{mM}$.
In the next stage, the effect of various concentrations of iron nano oxide on the Fenton oxidation of pyrene was investigated at optimum $\mathrm{H}_{2} \mathrm{O}_{2}$ concentration of $300 \mathrm{mM}$. The removal efficiency was increased with an increase in $\mathrm{Fe}^{3+}$ dosage up to $30 \mathrm{mM}$, and then decreased at higher concentrations (Figure 3). The pyrene removal reached $73 \%$ at the optimum concentration levels of $\mathrm{H}_{2} \mathrm{O}_{2}$ and iron nano oxide. As can be deducted from Figure 3 , the iron nano oxide concentration of $30 \mathrm{mM}$ and $\mathrm{H}_{2} \mathrm{O}_{2} / \mathrm{Fe}$ molar ratio of 10 were taken as the optimal values.

\section{The effect of contact time on pyrene removal}

The effect of reaction time on pyrene removal at optimum $\mathrm{H}_{2} \mathrm{O}_{2}$ and $\mathrm{Fe}^{3+}$ concentration was investigated. According to Figure 4, reaction time positively affected the removal efficiency and the pyrene removal of $99 \%$ was achieved after 6 hours of contact time. After all, the soil contaminated by an initial pyrene concentration of $100 \mathrm{mg} / \mathrm{kg}$ was completely removed under the following conditions: $\mathrm{H}_{2} \mathrm{O}_{2}$ concentration of $300 \mathrm{mM}, \mathrm{Fe}^{3+}$ concentration of $30 \mathrm{mM}, \mathrm{pH} 3$ and the reaction time of $6 \mathrm{~h}$.

\section{Effect of chelating agent on oxidation efficiency at neutral $\mathrm{pH}$}

Due to the operational problems with regard to Fenton oxidation at acidic $\mathrm{pH}$ in full scale applications such as soil matrix destruction, damages to native plant, and release of toxic metal, the ability of a CA to keep the iron catalyst in the solution at natural $\mathrm{pH}$ is highly considered for removal of organic pollutants in soil via Fenton oxidation. The pyrene removal in the presence of sodium pyrophosphate (as an inorganic CA) and EDTA, FA, HA and SC (as organic CA) at $\mathrm{H}_{2} \mathrm{O}_{2} / \mathrm{Fe}^{3+}$ molar ratio of $10, \mathrm{pH} 7$ and the contact time of $6 \mathrm{~h}$ was investigated at the pyrene initial concentration of $100 \mathrm{mg} / \mathrm{kg}$.

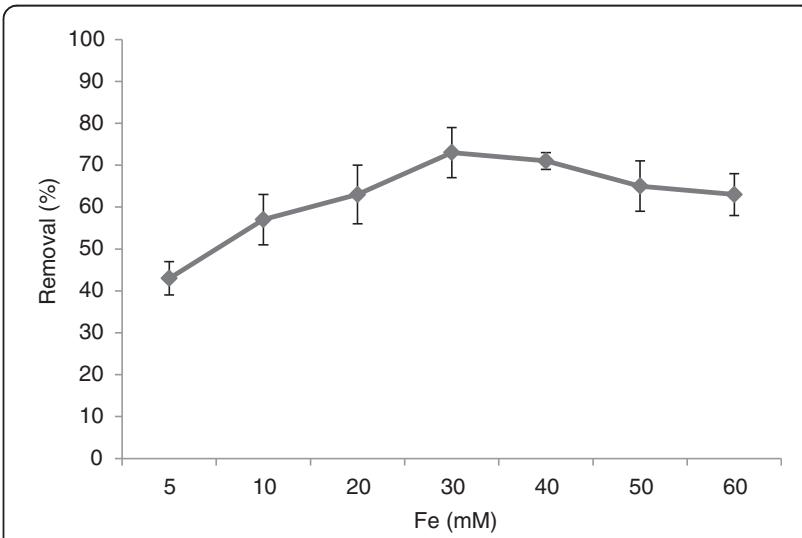

Figure 3 The pyrene removal efficiency versus varying $\mathrm{Fe}$ concentrations in optimum $\mathrm{H}_{2} \mathrm{O}_{2}$ concentration of $300 \mathrm{mM}$, reaction time of $30 \mathrm{~min}$ and $\mathrm{pH} 3$. 


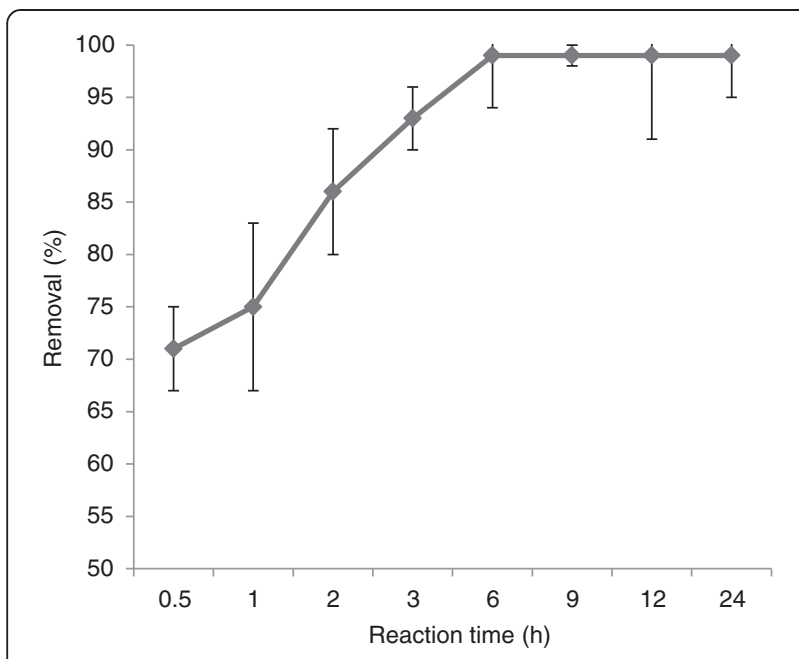

Figure 4 Effect of contact time on pyrene removal by Fenton oxidation in optimum $\mathrm{H}_{2} \mathrm{O}_{2}$ and $\mathrm{Fe}$ concentrations and $\mathrm{pH} 3$.

The removal efficiency was found to be $93 \%$ for sodium pyrophosphate and $86 \%, 75 \%, 72 \%$ and $71 \%$ for EDTA, SC, HA and FA, respectively (Figure 5). The effect of a number of chelating agents on pyrene removal efficiency from contaminated soil at optimum conditions was significant $(\mathrm{P}<0.019)$ according to non parametric Kruskal Wallis test. The results of statistical analysis are presented in Table 2.

Regarding the removal efficiency of $93 \%$ (obtained at $\mathrm{pH}$ 7, CA of pyrophosphate, $\mathrm{H}_{2} \mathrm{O}_{2}$ concentration of $300 \mathrm{mM}, \mathrm{Fe}^{3+}$ concentration of $30 \mathrm{mM}$ and the contact time of $6 \mathrm{~h}$ ), higher concentrations of pyrene (100 -500 $\mathrm{mg} / \mathrm{kg}$ ) were investigated to simulate actual conditions in the presence of other hydrocarbons with more cumulative concentration. By applying the optimum conditions of the modified Fenton oxidation, the residual

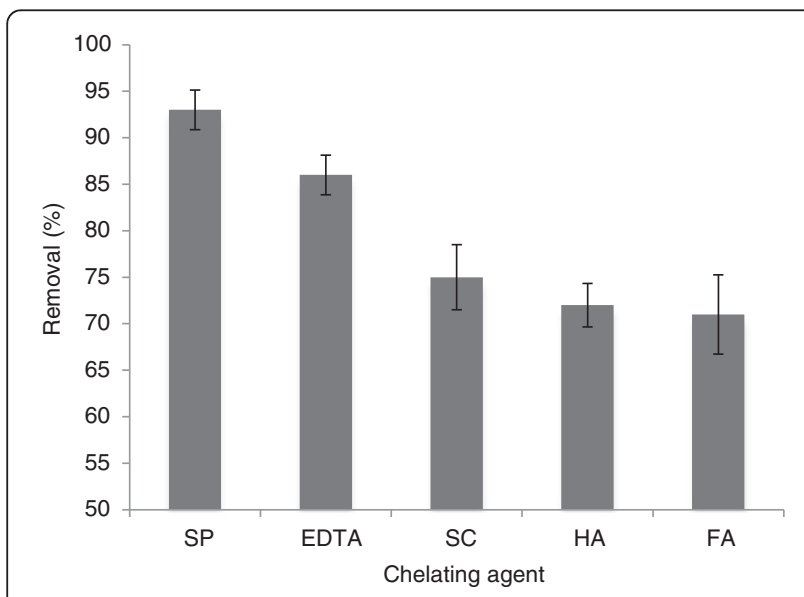

Figure 5 The pyrene removal efficiency for different CAs in $\mathrm{pH} 7, \mathrm{H}_{2} \mathrm{O}_{2}$ concentration of $300 \mathrm{mM}, \mathrm{Fe}^{3+}$ concentration of $30 \mathrm{mM}$ and Contact time of $6 \mathrm{~h}$.
Table 2 The statistical analysis of each chelating agent application (according to non parametric Kruskal Wallis test)

\begin{tabular}{ccc}
\hline Group & Mean removal \pm Std & P Value \\
\hline FA & $70 \pm 4.26$ & $P<0.019$ \\
HA & $72 \pm 2.34$ & \\
SC & $75 \pm 3.49$ & \\
EDTA & $86 \pm 2.14$ & \\
SP & $93 \pm 2.12$ & \\
\hline
\end{tabular}

pyrene was decreased to $6,16,27,56$ and $90 \mathrm{mg} / \mathrm{kg}$ at initial concentrations of 100,200,300, 400 and $500 \mathrm{mg} /$ $\mathrm{kg}$, respectively (Figure 6).

The effect of pollution aging on oxidation efficiency In order to investigate the efficiency of modified Fenton oxidation according to the optimum conditions obtained in the current study, a soil sample spiked by a pyrene solution of $100 \mathrm{mg} / \mathrm{kg}$ and aged up to one year, and also a real contaminated soil sample with different hydrocarbons were both subjected to the modified Fenton oxidation. After the extraction, the amounts of pyrene extracted in the aged and real soil sample were found to be 86.8 and $67 \mathrm{mg} / \mathrm{kg}$, respectively. However, the residual pyrene in the soil sample with aged contamination was $7.8 \mathrm{mg} / \mathrm{kg}$ providing the total removal of $91 \%$ for pyrene in the contaminated soil was obtained. The total residual pyrene in the aged soil sample was $21 \mathrm{mg} / \mathrm{kg}(13.2 \mathrm{mg} / \mathrm{kg}$, nonextracted; $7.8 \mathrm{mg} / \mathrm{kg}$, remaining after modified Fenton oxidation). The residual pyrene for the real soil sample was found to be $38 \mathrm{mg} / \mathrm{kg}$ (removal of $43 \%$ ).

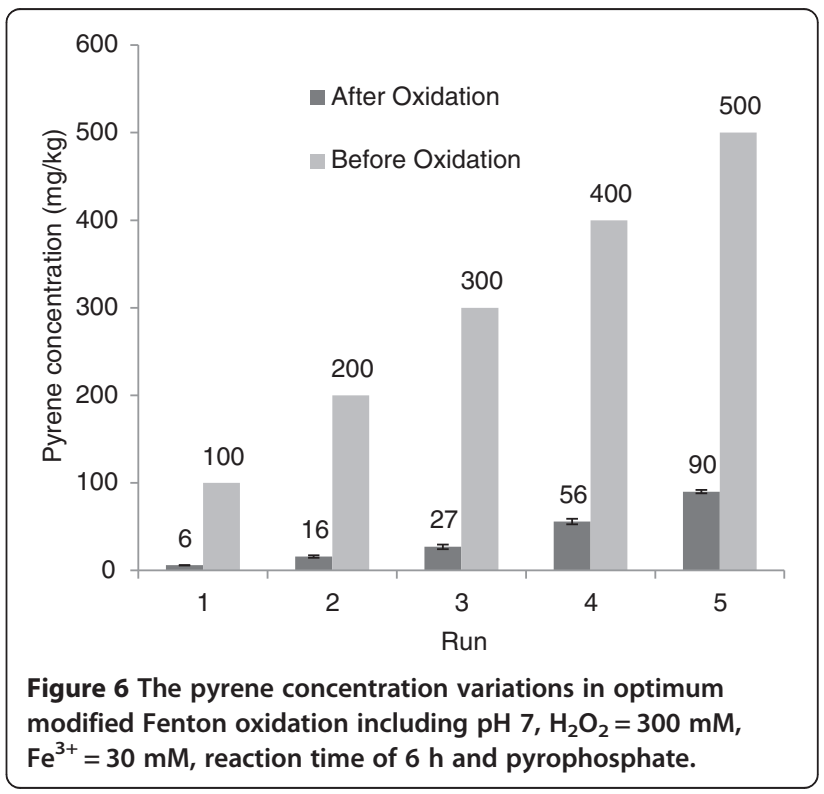




\section{Discussion}

The optimum dosages of $\mathrm{H}_{2} \mathrm{O}_{2}$, iron catalyst and consequently $\mathrm{H}_{2} \mathrm{O}_{2} / \mathrm{Fe}$ ratio are critical operational issues in Fenton oxidation. In various studies, a range of concentrations and molar ratios are introduced as optimum conditions. The principal reasons for this variation can arise from the type of pollutant, contaminant concentration, reaction time, age of pollution and the inorganic and organic characteristics of soil [10]. Since Fenton oxidation obeys pseudo first order kinetics, increase in reagent dosages effectively enhances the process efficiency [10].

In the current study, pyrene removal increased at higher $\mathrm{H}_{2} \mathrm{O}_{2}$ concentrations, but no considerable improvement was observed at $\mathrm{H}_{2} \mathrm{O}_{2}$ concentrations beyond $300 \mathrm{mM}$. Hydroxyl radicals produced by reaction 1 is the main factor for the destruction of persistent organic contaminants. In order to have continuous production of hydroxyl radicals, $\mathrm{Fe}^{3+}$ produced from reaction 1 should be reduced to $\mathrm{Fe}^{2+}$ by an additional reaction (reaction 2). The pyrene removal is restricted, when sufficient iron catalyst and excess amounts of $\mathrm{H}_{2} \mathrm{O}_{2}$ are present. Consequently, $\mathrm{H}_{2} \mathrm{O}_{2}$ in excess consumes considerable amounts of $\mathrm{Fe}^{2+}$ leading to a shortage of $\mathrm{Fe}^{2+}$ in the reaction. This could explain why the removal efficiency falls at higher $\mathrm{H}_{2} \mathrm{O}_{2}$ concentrations (i.e., >300 mM).

The optimum concentration of iron catalyst is also very important. In this study, iron nano oxide at $30 \mathrm{mM}$ was determined to be the best dosage. At higher values, pyrene removal efficiency was increased, but alongside an observed increase in the amounts of excess sludge, as a negative side effect of Fenton oxidation. Applying other iron types including zero valent iron nano particles or iron nano oxides instead of soluble iron $\left(\mathrm{Fe}^{2+}\right)$ to decrease the excess sludge production, is one of the most important modifications in the conventional Fenton reaction. The excess sludge level is considerably decreased during Fenton oxidation when iron nano particles are applied as the catalyst for $\mathrm{H}_{2} \mathrm{O}_{2}$ dissociation [23]. On the other hand, in presence of excess amounts of $\mathrm{Fe}^{2+}$, $\mathrm{H}_{2} \mathrm{O}_{2}$ is either turned into water via side reactions (instead of radical production) or acts as a radical scavenger [24]. Kulic et al (2006) claimed that increasing the Fenton reagents led to a $15 \%$ improvement in removal of PAHs [11]. Nam et al. [25] reported that an increase in the $\mathrm{Fe}^{2+} / \mathrm{H}_{2} \mathrm{O}_{2}$ ratio favored only hydrophobic compounds like three, four and five ring PAHs. Since pyrene is a four-ring $\mathrm{PAH}$, the removal enhancement at higher reagent concentrations can be justified [25].

In a similar study as reported here, Sun et al. [26] reported that the optimum $\mathrm{H}_{2} \mathrm{O}_{2}$ and $\mathrm{Fe}^{2+}$ concentrations they found were 200 and $20 \mathrm{mM}$, respectively; with a $\mathrm{H}_{2} \mathrm{O}_{2} / \mathrm{Fe}^{2+}$ molar ratio of 10) [26]. In further related studies, $\mathrm{H}_{2} \mathrm{O}_{2} / \mathrm{Fe}^{2+}$ molar ratios of 5 to 25 were reported as the optimum values which is in agreement with the current study finding [27]. The low $\mathrm{pH}(=3)$ needed for conventional Fenton oxidation is a major difficulty in full scale applications. Generally, Low $\mathrm{pH}$ is an unsuitable alternative compared to bioremediation, especially in soil remediation. It enhances heavy metal mobility and changes the ecosystem of the treated soil. The chelating agents are used at neutral $\mathrm{pH}$ to overcome this limitation. In the current study, pyrene removal of $93 \%$ was obtained by the usage of SP as an inorganic CA at $\mathrm{pH} \mathrm{7,} \mathrm{which} \mathrm{was} \mathrm{more} \mathrm{than} \mathrm{the} \mathrm{maximum} \mathrm{removal} \mathrm{of}$ 86\% obtained for EDTA amongst organic CAs. It is believed that EDTA is superior to other organic CAs like FA, HA and SC because of its strong five membered structure yielding the tight binding EDTA-iron complex which is highly stable even at neutral soil $\mathrm{pH}$ [16]. Hence, inorganic CAs cannot compete with hydroxyl radicals and therefore cannot increase the TOC content of the soil. However, they can enhance the pyrene removal through modified Fenton oxidation more than that of organic CAs [16].

Venny et al. [16] reported that the flouranthene removal by a modified Fenton reaction using SP (as CA) was $78 \%$, which is lower than the values obtained in the current study [16]. The differences in the reaction time, the type of $\mathrm{PAH}$, soil and oxidation conditions maybe explain this result. Also, Kanel et al reported 85\% removal for phenanthrene in a Fenton like oxidation at neutral $\mathrm{pH}$ after $3 \mathrm{~h}$ contact time [12].

Generally, hydrocarbon removal decreases along with contamination aging, which is confirmed by the current study findings. Pollution aging leads to migration of pyrene from easily accessible to difficult sites (sequestration), which reduces the molecule oxidation. Sequestration is a natural process happening in soil which reduces the chemical and biological remediation efficiency of hydrophobic organic pollutants [28]. Fenton oxidation can alter the combination state of hydrophobic organic compounds and enhance their desorption [27].

In the current work, pyrene removal in freshly contaminated soil was observed to be greater than that of the soil sample with aged pollution providing the same experimental conditions are applied to all samples. As a matter of fact, pyrene removal in the real soil sample contaminated with a pyrene concentration of $67 \mathrm{mg} / \mathrm{kg}$ was relatively low (only 43\%). This low removal efficiency can be attributed to the presence of other hydrocarbons scavenging hydroxyl radicals and also the contamination aging. This finding is in agreement with previous work by Sun and Yan [26].

The removal efficiency for an initial pyrene concentration of $40 \mathrm{mg} / \mathrm{kg}$ was reported to decrease from $88.9 \%$ in freshly contaminated soil to $74.7 \%$ in soil aged for 
30 days [26]. Consequently, the full scale applications of modified Fenton oxidation for PAHs removal, requires higher reagent concentrations compared to lab scale amounts.

For simulation of actual conditions with cumulative concentrations of hydrocarbons, higher pyrene concentrations were studied. The pyrene removal efficiency for initial concentrations of 400 and $500 \mathrm{mg} / \mathrm{kg}$ was $86 \%$ and $82 \%$, respectively. These removal values would be even less in actual conditions with aging of the pollution. Also, when the removal efficiency is considerably high value, it will breakdown a large portion of pyrene or metabolizes it, leading to relatively easy degradation via biological processes. The pyrene removal at optimum conditions obtained in this study was $90 \%$ for an initial pyrene concentration of $300 \mathrm{mg} / \mathrm{kg}$.

\section{Conclusions}

According to the findings of this study and the considerable benefits obtained from the use of iron nanoparticles, including less excess sludge and a faster reaction rate, it can be concluded that the modified Fenton oxidation using iron nano oxides at optimum concentrations of $\mathrm{H}_{2} \mathrm{O}_{2}$ and $\mathrm{Fe}^{3+}$ and also in the presence of sodium pyrophosphate as inorganic CA was an efficient alternative in lab scale experiments for remediation or pre-treatment of soils contaminated by pyrene at neutral $\mathrm{pH}$. Therefore, in the future, more studies in full scale applications along with economic analysis with other technologies should be completed to assess the process feasibility and viability for field applications.

\section{Abbreviations}

AOPs: Advanced oxidation processes; CA: Chelating agent; EDTA: Ethylene diamine tetra acetic acid; FA: Fulvic acid; $\mathrm{HA}$ : Humic acid; $\mathrm{H}_{2} \mathrm{O}_{2}$ : Hydrogen peroxide; OA: Oxalic acid; PAH: Polycyclic aromatic hydrocarbon; SC: Sodium citrate; SOMs: Soil organic matters; USEPA: United stated Environmental Protection Agency; XRD: X-ray Diffraction; XRF: X-ray fluorescence.

\section{Competing interests}

The authors declare that they have no competing interests.

\section{Authors' contributions}

This paper was extracted from a PhD thesis and Dr AR, Dr NJ and Dr GM were designed and directed the study as supervisor and consulter and participated in its coordination and helped to draft the manuscript. SJ was the student who did the experiments and wrote the paper. All authors read and approved the final manuscript.

\section{Acknowledgements}

The authors would like to appreciate Tarbiat Modares University for its supports in term of this research project.

\section{Author details}

${ }^{1}$ Department of Environmental Health Engineering, School of Medical Sciences, Tarbiat Modares University, Tehran, Iran. ${ }^{2}$ Biotechnology Research Center, Research Institute of Petroleum Industry, Tehran, Iran. ${ }^{3}$ Department of Environmental Health Engineering, School of Public Health, Environmental Technology Research Center, Ahwaz Jondishapour University of Medical Sciences, Ahwaz, Iran.
Received: 5 September 2012 Accepted: 29 June 2013

Published: 16 July 2013

\section{References}

1. Rezaei Kalantary R, Badkoubi A, Mohseni-Bandpi A, Esrafili A, Jorfi S, Emad Dehghanifard E, Baneshi M: Modification of PAHs Biodegradation with Humic Compounds, Soil and Sediment Contamination. Soil and sediment contamination: An International Journal 2013, 22:185-198.

2. Nadarajah N, Van HJ, Pannu J, Singh A: Enhanced transformation of polycyclic aromatic hydrocarbon using a combined Fenton's reagent, microbial treatment and surfactants. Applied Microbial Biotechnology 2002, 59:540-544.

3. Mohsenzadeh F, Chehregani Rad A, Akbari M: Evaluation of oil removal efficiency and enzymatic activity in some fungal strains for bioremediation of petroleum-polluted soils. Iranian Journal of Environmental Health Sciences \& Engineering 2012, 9:26.

4. Srikanth RM, Naresh B, Leel T, Prashanthi M, Madhusudhan N, Dhanasri G, Devi P: Biodegradation of phenanthrene with biosurfactant production by a new strain of Brevibacillus sp. Bioresour Technol 2010, 101:7980-7983.

5. Chung MK, Hu R, Cheung KC, Wong MH: Pollutants in Hong Kong soils: polycyclic aromatic hydrocarbons. Chemosphere 2006, 67:464-473.

6. Zhou W, Zhu L: Efficiency of surfactant-enhanced desorption for contaminated soils depending on the component characteristics of soilsurfactant- PAHs system. Environ. Pollution 2007, 147:66-73.

7. Watts R, Stanton P, Howsawkeng J, Teel A: Mineralization of a sorbed polycyclic aromatic hydrocarbon in two soils using catalyzed hydrogen peroxide. Water Res 2002, 36:4283-4292.

8. Ferrarese E, Andreottola G, Oprea L: Remediation of PAH-contaminated sediments by chemical oxidation. J Hazard Mater 2008, 152:128-139.

9. Lin Q, Yingxu C, Wang Z, Wang Y: Study on the possibility of hydrogen peroxide pretreatment and plant system to remediate soil pollution. Chemosphere 2004, 57:1439-1447.

10. Yap C, Gan S, Ng H: Fenton based remediation of polycyclic aromatic hydrocarbons-contaminated soils. Chemosphere 2011, 83:1414-1430.

11. Kulik N, Goi A, Trapido M, Tuhkanen T: Degradation of polycyclic aromatic hydrocarbons by combined chemical pre-oxidation and bioremediation in creosote contaminated soil. J Environ Manage 2006, 78:382-391.

12. Kanel SR, Neppolian B, Choi H, Yang JW: Heterogenous catalytic oxidation of phenanthrene by hydrogen peroxide in soil slurry: kinetic, mechanism, and implication. Soil Sediment Contamination 2003, 12:101-117.

13. Valderrama C, Alessandri R, Aunola T, Cortina JL, Gamisans X, Tuhkanen T: Oxidation by Fenton's reagent combined with biological treatment applied to a creosote-contaminated soil. J Hazard Mater 2009, 166:594602.

14. Yeh CK, Hsu C, Chiu C, Huang K: Reaction efficiencies and rate constants for the goethite-catalysed Fenton-like reaction of NAPL-form aromatic hydrocarbons and chloroethylenes. Journal of Hazardous Material 2008 151:562-569.

15. Georgi A, Schierz A, Trommler U, Horwitz C, Collins T, Kopinke F: Humic acid modified Fenton reagent for enhancement of the working $\mathrm{pH}$ range. Applied Catalyst B-Environment 2007, 72:26-36.

16. Venny, Gan S, Ng HK: Inorganic chelated modified-Fenton treatment of polycyclic aromatic hydrocarbon (PAH)-contaminated soils. Chem Eng J 2012, 180:1-8

17. Kanel SR, Neppolian B, Jung H, Choi H: Comparative removal of polycyclic aromatic hydrocarbons using iron oxide and hydrogen peroxide in soil slurries. Environ Eng Sci 2004, 21:741-751.

18. Rusevova K, Kopinke F, Georgi A: Nano-sized magnetic iron oxides as catalysts for heterogeneous Fenton-like reactions-Influence of $\mathrm{Fe}(\mathrm{II}) / \mathrm{Fe}$ (III) ratio on catalytic performance. J Hazard Mater 2012, 241-242:433-440.

19. Grieger K, Fjordbøge A, Hartmann N, Eriksson E, Bjerg P, Baun A: Environmental benefits and risks of zero-valent iron nanoparticles (nZVI) for in situ remediation: Risk mitigation or trade-off. J Contam Hydrol 2010, 118:165-183.

20. Khan E, Wirojanagud W, Sermsal N: Effects of Iron type in Fenton reaction on mineralization and biodegradability enhancement of hazardous organic compounds. J Hazard Mater 2009, 161:1024-1034.

21. Bogan B, Trbovic V: Effect of sequestration on PAH degradability with Fenton's reagent: roles of total organic carbon, humin, and soil porosity. $J$ Hazard Mater 2003, 100:285-300. 
22. PAHs Extraction Method. www.trincoll.edu/ henderso/textfi 1/416\%20notes/ 3550b.pdf.

23. Liao C, Chung T, Chen W, Kuo S: Treatment of pentachlorophenolcontaminated soil using nano-scale zero-valent iron with hydrogen peroxide. Journal of Molecular Catalysis A: Chemical 2007, 265:189-194

24. Choi K, Lee W: Enhanced degradation of trichloroethylene in nano-scale zero-valent iron Fenton system with Cu(II). J Hazard Mater 2012, 211-212:146-153.

25. Nam K, Rodriguez W, Kukor JJ: Enhanced biodegradation of polycyclic aromatic hydrocarbons by biodegradation combined with a modified Fenton reaction. Chemosphere 2001, 45:11-20.

26. Sun $H$, Yan Q: Influence of pyrene combination state in soils on its treatment efficiency by Fenton oxidation. J Environ Manage 2008, 88:556-563.

27. Moon B, Park Y, Park K: Fenton oxidation of Orange II by pre-reduction using nanoscale zero-valent iron. Desalination 2011, 268:249-252.

28. Jonsson S, Persson Y, Frankki S, Bavel B, Lundstedt S, Haglund P, Tysklind M: Degradation of polycyclic aromatic hydrocarbons (PAHs) in contaminated soils by Fenton's reagent: a multivariate evaluation of the importance of soil characteristics and PAH properties. J Hazard Mater 2007, 149:86-96.

doi:10.1186/2052-336X-11-17

Cite this article as: Jorfi et al:: Pyrene removal from contaminated soils by modified Fenton oxidation using iron nano particles. Journal of Environmental Health Sciences \& Engineering 2013 11:17.

\section{Submit your next manuscript to BioMed Central and take full advantage of:}

- Convenient online submission

- Thorough peer review

- No space constraints or color figure charges

- Immediate publication on acceptance

- Inclusion in PubMed, CAS, Scopus and Google Scholar

- Research which is freely available for redistribution 